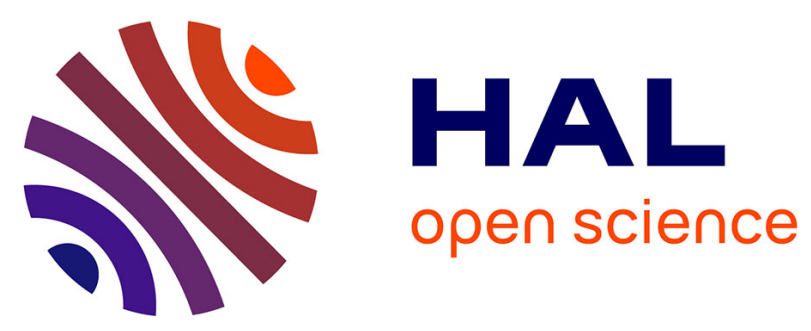

\title{
Test method for boom suspension influence on spray distribution. Part II : Validation and use of a spray distribution model
}

Yvan Lardoux, Carole Sinfort, Patrik Enfält, André Miralles, Francis Sevila

\section{- To cite this version:}

Yvan Lardoux, Carole Sinfort, Patrik Enfält, André Miralles, Francis Sevila. Test method for boom suspension influence on spray distribution. Part II: Validation and use of a spray distribution model. Bioprocess and Biosystems Engineering, 2007, 96 (2), pp.161-168. 10.1016/j.biosystemseng.2006.10.003 . lirmm-00319302

\section{HAL Id: lirmm-00319302 \\ https://hal-lirmm.ccsd.cnrs.fr/lirmm-00319302}

Submitted on 8 Sep 2008

HAL is a multi-disciplinary open access archive for the deposit and dissemination of scientific research documents, whether they are published or not. The documents may come from teaching and research institutions in France or abroad, or from public or private research centers.
L'archive ouverte pluridisciplinaire HAL, est destinée au dépôt et à la diffusion de documents scientifiques de niveau recherche, publiés ou non, émanant des établissements d'enseignement et de recherche français ou étrangers, des laboratoires publics ou privés. 
Author-produced version of the article published in Biosystems Engineering, 96(2), 161-168.

Original version available at www.elsevier.com - doi:10.1016/j.biosystemseng.2006.10.003

\title{
Test Method for Boom Suspension Influence on Spray Distribution, Part II:
}

\section{Validation and Use of a Spray Distribution Model}

\author{
Y. Lardoux ${ }^{1}$, C. Sinfort ${ }^{2}$, P. Enfält ${ }^{3}$, A. Miralles ${ }^{4}$, F. Sevila ${ }^{5}$
}

${ }^{1}$ Laboratoire de Mécanique, Physique et Géosciences, quai Frissard, BP 540, 76058 Le Havre cedex, France yvan.lardoux@univ-lehavre.fr

${ }^{2}$ UMR « Information et Technologie pour les Agro-bio Procédés », ENSA M., 2 pl. Viala, 34060 Montpellier,

$$
\text { France-sinfort@ensam.inra.fr }
$$

${ }^{3}$ Swedish University of Agricultural Sciences, Dept of Agricultural Engineering, S-750 07 Uppsala, Sweden -

\section{patrik@seedgard.se}

${ }^{4} \mathrm{UMR}$ « Territoires, Environnement, Télédétection et Informations Spaciales », Maison de la Télédétection, 500, rue Jean-François Breton, 34093 Montpellier Cedex 5, France- andre.miralles@ teledetection.fr

${ }^{5}$ ENSA Toulouse, Av. de l'Agrobiopole, BP 32607, Auzeville Tolosane, 31326 Castanet Tolosan -

francis.sevila@ensat.fr

\begin{abstract}
In the first part of this paper, an experimental study of the influence of boom movements on ground distribution showed that a geometric static model should correctly be used for simulations. Such model was developed in Cemagref. The objective of this second part is to validate the results of this model for several kinds of excitation in laboratory and field conditions: laboratory validation used a conveyor and a shaking platform to reproduce pure vertical and horizontal movements; field validation was assessed on both concrete and field tracks to analyse combined movements. Then the model was used to define an evaluation method for sprayer boom behaviour at farm level. The concept is for the sprayer to travel over a bump, to measure boom movements and to simulate the distributions. The evenness is assessed through the coefficient of variation (CV) and the percentage of area correctly sprayed.
\end{abstract}

Keywords: sprayer, distribution, nozzles, boom, validation 
Author-produced version of the article published in Biosystems Engineering, 96(2), 161-168.

Original version available at www.elsevier.com - doi:10.1016/j.biosystemseng.2006.10.003

\section{Introduction}

This study was part of a European project (SPECS, 1998) to develop a boom test method at the farm level. This method should allow to test the performance of sprayers in use relatively to the uniformity of the ground distribution and to give advice for rapid corrections. Processing speed, easiness of use, accuracy and cost considerations were the key points of this project.

In the first part of this article (Lardoux et al.,2007), an experimental approach was described for the analysis of the importance of the main movements on the distribution. Roll and yaw movements were shown to have important effects on unevenness and it was concluded that, when these movements are uncoupled, a geometric representation should be able to predict ground distributions with sufficient accuracy. If such conclusion could be enlarged to the combined movements of the boom, an efficient test method could then follow the following steps: apply appropriate mechanical excitation on the sprayer, measure boom displacements and model ground distribution. With a model of low complexity (i.e. with no necessity of heavy means of computation and with a friendly interface), such protocol should allow results to be obtained quickly when an experimental approach based on distributions measurements would be very much longer to setup and less reproducible.

The main objective of this work was then to check the ability of a low complexity model, based on a geometric representation of the sprays, to predict distributions for uncoupled and for combined movements of the boom. Then, appropriate mechanical excitations to test the sprayers were discussed and a test method was designed both for the excitation and for boom measurements at the farm level. Finally, the ability of the combine use of these methods (mechanical excitation, boom measurement and simulation) to estimate the behaviour of the booms at the farm level was assessed.

\section{Materials and methods}

\subsection{Distribution model}

To compute distribution on soil knowing boom movements, a geometric approach can be proposed as in De Baerdemaker et al. (1983), Chaplin and Wu (1989), Ramon and De Baerdemaeker (1996), Pochi and Vanucci (2002) and Lebeau (2003). Such a model was also developed in the Cemagref institute (the French Institute for Agricultural and Environmental Engineering Research) by Sinfort et al. (1994). This model can predict spray distributions under a moving boom in a two-dimensions. The simulation software inputs are the boom movements and tables of nozzle flow-rates compiled with measurements made with a patternator, at several heights. The 2D distributions are estimated on a plane rectangular surface divided in elementary cells of $50 \mathrm{~mm}$ x $50 \mathrm{~mm}$ in size, from the successive positions of the nozzles, obtained from measured positions of the boom. 
Author-produced version of the article published in Biosystems Engineering, 96(2), 161-168.

Original version available at www.elsevier.com - doi:10.1016/j.biosystemseng.2006.10.003

The distribution of each nozzle is described with one dimensional patterns of $50 \mathrm{~mm}$ elements. These patterns are modified depending on the height and the vertical angle of the nozzle. The flow-rates constituting the patterns are distributed in the cells dividing the ground surface. The principle is synthesised in Fig. 1.

\subsection{Validation tests}

To validate the model described above, it was proposed to compare measured and simulated distributions for movements obtained in controlled conditions. Two validation steps were proposed. The first one used a conveyor able to shake the boom with roll or yaw oscillations during its ride (uncoupled movements). The second one was based on riding tests on tracks, allowing to obtain combined vertical and horizontal movements. The measurement method for the distributions was the same as the one used in the first part and described in Enfält $e t$ al; (1997). It uses image analysis of papers sprayed with Nigrosine water soluble. This method gives accurate and rapid results but under-estimates the doses when the height of the boom increases, probably because of the calibration step and maybe also because the evaporation increases with the distance travelled by the droplets. To compare measured and simulated distributions, the percentage of area with correct, over and under spraying (the correct treatment was defined with $+/-15 \%$ from the mean sprayed dose (Sinfort et al., 1994) and the coefficient of variation $(\mathrm{CV})$ were used. As seen in the first part, we also defined another indicator, $\left(S_{p}\right)$, based on the definition of scalar product of histograms used in image analysis methods as a correlation coefficient between two images (Rabatel, 1991):

$$
S_{P}=\frac{\sum_{i} m_{i} m_{i}^{\prime}}{\sqrt{\sum_{i} m_{i}^{2} m_{i}^{\prime 2}}}
$$

where $m_{i}$ is the proportion of cells behaving to the $\mathrm{i}^{\text {th }}$ class of amount of product (or of grey level) for the first distribution (or the first image) and $m_{i}^{\prime}$ is the same for the second distribution (or the second image).

\subsubsection{Uncoupled movements}

The conveyor with its shaking-platform was described in the first part of this article. The experimental study already showed that static distributions (equivalent to simulations with a horizontal boom, without any roll or yaw movement) were in good agreement with the measured ones although velocity effect and interactions between sprays are not considered. The results of the models were then compared with experimental distributions for roll and yaw movements. $+/-5^{\circ}$ oscillations were reproduced for roll and yaw at several frequencies: $1.08,0.77$ and $0.49 \mathrm{~Hz}$. These movements were tested with two forward speeds: 6 and $10 \mathrm{~km} / \mathrm{h}$. Boom height was $50 \mathrm{~cm}$ and the nozzles were 
Author-produced version of the article published in Biosystems Engineering, 96(2), 161-168.

Original version available at www.elsevier.com - doi:10.1016/j.biosystemseng.2006.10.003

Teejet XR 11004VS. Boom positions were registered from the command device of the shaking platform.

Distributions were obtained on an area of $4.50 \mathrm{~m}$ in the forward direction and $4.45 \mathrm{~m}$ wide.

\subsubsection{Combined movements}

Within the SPECS consortium, two tracks were selected to obtain combined movements: the $100 \mathrm{~m}$ long concrete standard test track for seat tests built in Cemagref, Anthony, France according to ISO 5008 standard (bumpy track) and a $47 \mathrm{~m}$ ploughed field track covered with grass which topography was measured every $15 \mathrm{~cm}$ along each wheel path (ISO, 1979). Three sprayers were tested: two were of same type (A) with a new and an old one, the third one was a new one of another type (B). The type A sprayers were mounted ones and their booms were $12 \mathrm{~m}$ long while the type B sprayer was a trailed one with a $15 \mathrm{~m}$ boom. The three sprayers were tested on the bumpy track with three replicates but only the new type A sprayer was tested on the field, with one replicate only because the field topography was modified by the passage of the sprayer. Forward speed was 6 $\mathrm{km} / \mathrm{h}$ and the tank was almost empty. Distributions were obtained by spraying Nigrosine mixture on papers placed along the tracks during the tests (Fig. 2) and by simulation. The measurement area was placed under the right part of the sprayer and sized at $8.95 \mathrm{~m}$ in the driving direction for a $4.25 \mathrm{~m}$ width. To measure the boom positions necessary for the simulations, the tracks were reproduced on the track simulator built in Cemagref Montpellier and already described in Sinfort and Bonicelli (1989). This device moves vertically the front and the rear axles of the tractor with four hydraulic servo-jacks that reproduce the varying altitudes of the track as if the tractor was travelling along it. Boom tip movements were measured with a device using an infrared sensor described in Sinfort et al. (1994). Roll and yaw movements were computed from these measurements knowing the position of the boom centre. This latter was obtained from the command part of the simulator. To run the model software, the distributions of the XR04 nozzle were measured on a patternator consistent with ISO 5682 standard, at several heights from $0.20 \mathrm{~m}$ to $1 \mathrm{~m}$, every $0.1 \mathrm{~m}$ (ISO, 1981).

\section{Results and discussion}

\subsection{Uncoupled movements}

\subsubsection{Yaw movement}

Grey level representations of the experimental and modelled distributions are shown in Fig. 3 in association with the boom rotation angle, for the test at $0.77 \mathrm{~Hz}$ and $6 \mathrm{~km} / \mathrm{h}$. Forward direction is from the top to the bottom of the figure. These distributions look similar: the model correctly predicts the areas over-sprayed, when the boom velocity decreases. 
Author-produced version of the article published in Biosystems Engineering, 96(2), 161-168.

Original version available at www.elsevier.com - doi:10.1016/j.biosystemseng.2006.10.003

Results of analysis are given in Table 1. As expected, mean doses are under-evaluated for experimental results but they remain constant for all the tests.

The coefficients of variation, $\mathrm{CV}$, the over, under and correctly sprayed areas, are very similar in experimental and simulated distributions. The values for the CV are about $40 \%$ and correctly spray areas about $30 \%$. The scalar products of histograms $S_{p}$ are all greater than 0.97 confirming the similitude of the distributions.

\subsubsection{Roll movement}

Here again important similitude appears between simulated and measured patterns (example in Fig. 4) as confirmed by the scalar products of histograms $S_{p}$ given in Table 2. Spray unevenness due to nozzle overlap are correctly reproduced. However, some over-sprayed zones are not reproduced. This can be explained because the experimental method gives variable doses depending on the height although the model always computes the same dose.

Nevertheless, as shown in Table 2, the model gives higher CV values and lower percentages of correctly sprayed areas.

\subsection{Combined movements}

An example of experimental and modelled distributions is shown in Fig. 5, for the sprayer type B on the bumpy track. The model correctly reproduces the positions of the five over-sprayed areas measured but some of them are slightly shifted. More generally, the simulated distribution is less even than the measured one. The correlation coefficients, although smaller than in the previous tests, remain acceptable: roundly 0.90 (Table 3). Table 3 shows that the performances of each sprayer relatively to the distribution are variable: on the bumpy test track, the trailed sprayer type B gives the most even distributions. Obviously, the old sprayer has worse CVs than the new one and better behaviour is observed on the field track, which was much smoother than the bumpy one.

The same tendencies are observed from experimental and simulated patterns.

The same differences between measurements and simulations are always observed: higher doses, higher CVs and smaller correctly sprayed areas on the simulations. Measured doses show great variations (20\% for the old type A sprayer) but it maybe comes from the distribution measurement method. For the measured distributions, the CVs are between 20 and 35\%. The differences on the values of the CV between simulations and measurements are more important (about 10\%). An explanation is that the command of the track simulator uses squared signals and does not take the smoothing effect of the tyres into account. Mechanical excitations are then always higher than in real conditions. Furthermore, the method does not consider the deformations of the boom as only the tip 
Author-produced version of the article published in Biosystems Engineering, 96(2), 161-168.

Original version available at www.elsevier.com - doi:10.1016/j.biosystemseng.2006.10.003

of the boom positions are measured. The boom is then supposed to be rigid and the displacements of the nozzles are consequently over estimated. Spray dynamic effect could also have a smoothing effect that is not taken into account by the model.

The model could be improved by using a one-dimensional patternation of nozzles in dynamic conditions. These new data would be compatible with the present software. Moreover, a stochastic approach could be added to take into account the intensity of wind turbulence

\section{Definition of a field sprayer test}

The simulations give worse results than measurements, but this can be explained by the imperfections in the step calibration of the measurement method and in the reproductions of the movements with the track simulator. Taking into account the good results of the model for the laboratory tests, the model was assessed to correctly reproduce the evenness of the distributions and to predict the behaviour differences of the sprayers. It was then necessary to find a way to shake the sprayers and to obtain boom displacements in a way compatible with the objectives of the project: use at farm, low cost, robustness, test repeatability.

Several methods were already developed to test field sprayer movements. Some authors proposed to test the sprayers directly in fields conditions, with measurements of boom accelerations (Speelman \& Jansen, 1994) or boom displacements with laser sensors (Vannuci et al., 1992). But this method did not comply with the requirement of repeatability. Langenakens et al. (1995) used hammer tests on the boom to provide a modal analysis of its dynamics behaviour and simulate movements and then distributions for some standard configurations. Here, it is proposed to use a more global method, based on driving the sprayers on a simple bump placed on a rigid flat track (concrete or macadam, for instance). Acceleration and deceleration distances can be very short $(2 \mathrm{~m})$ and a distance of $15 \mathrm{~m}$ is enough to perform a test. A pyramidal bump shape was selected to create a large band frequency signal able to excite all the resonance frequencies of any tested machine.

Movements are measured with an image analysis device that detects a target fixed on the boom tip. This method was described in Sinfort et al. (1998); a picture and a chart showing its principle are given in Fig. 6.

A spraying test was organised for the new sprayer $A$ with the experimental method of Enfält et al. (1997) to check if, with this testing method, the distribution model could give a correct result. The resulting distributions are shown in Fig. 7 with the over, under and correctly sprayed areas. After the bump, the boom had two important horizontal oscillations. They were responsible of two over-sprayed areas as observed in both measured and simulated distributions. In the measured distribution, longitudinal unevenness appears due to the overlap of the nozzles. In the simulated distribution, the effect of the boom movements are highlighted, giving transversal 
Author-produced version of the article published in Biosystems Engineering, 96(2), 161-168.

Original version available at www.elsevier.com - doi:10.1016/j.biosystemseng.2006.10.003

unevenness which was not measured. The value for the scalar product of histograms $S_{p}$, corresponding to the measured and simulated ground spray distributions, is 0.9217 , confirming that the similarity of the distributions is acceptable.

The values obtained for the $\mathrm{CV}$ are $53 \%$ and $64 \%$ for the measured and modelled distributions, respectively, while the percentages of areas correctly sprayed are $41 \%$ and $18 \%$. This confirms that the measurement method under-estimates the unevenness while the model approach over-estimates it. Here again, the measurement of the boom positions, which is based on the detection of the boom tip, can be a cause of error as it does not consider the deformations of the boom. This error becomes more important with the largest booms due to the articulation joints between the sections. The model should then not be used to obtain realistic values but it is expected to give good discrimination between different behaviours.

It was then proposed to test the method with numerous used sprayers with varying frames (Sinfort et al., 1998).

The values for the CV of the spray deposit distributions was found to vary from 13 to $34 \%$ showing that the proposed method was sensible enough and then suitable for the objectives of the project.

\section{Conclusion}

The results show that the model gives very good predictions for laboratory tests with pure vertical and horizontal movements. For combined movements, modelled and measured distributions have the same features but the same differences are always observed: lower doses, lower values for the coefficient of variation and higher surfaces with correct spraying for measurement distributions. Three combined factors are mainly responsible: the calibration step of the measurement method for the distributions, the method for the boom position measurements that consider that the boom is rigid and the spray dynamic effect which is not taken into account. Nevertheless, this geometric approach is a satisfactory method to quickly estimate the ground spray distribution under a rigid moving boom. The model could be improved with the use of dynamic nozzle patterns and with an estimation of the turbulence effect.

The proposed method, using a bump test appears to be a good compromise to test field sprayers in use at the farm level and complies with the given requirements. The results over-estimate unevenness and the deformations of the boom should be taken into account to a better assessment of the behaviour. For instance, the quality of the measurements could be improved by measuring movements at each section tip of the boom. Overall, the simulated distributions, that highlight the behaviour of the booms, provide an interesting tool that fulfils the objectives of the project. 
Author-produced version of the article published in Biosystems Engineering, 96(2), 161-168.

Original version available at www.elsevier.com - doi:10.1016/j.biosystemseng.2006.10.003

\section{Acknowledgments}

Thanks or due to the other partners involved in the SPECS project: 'European system for field sprayer inspection at the farm level' - Contract EEC CT 921170: Katholic University of Leuven (Belgium), Biologische Bundesanstalt für Land und Fortwirtschaft (Germany), Swedish University of Agricultural Sciences (Sweden), Istituto Sperimentale per la Meccanizzazione Agricola (Italy), Landesanstalt für Pfanzenschuts (Germany), Cemagref (France). This was supported by the Cemagref team of the Technologies and Equipment for Agrosystems Laboratory (J.L. Vigneau, J.F. Trani, D. Virgile, X. Ribeyrolles, J.-M. Fatou, A. Miralles, V. Polvèche, B. Bonicelli) (Unité de Recherche TEMO - Technologie et Equipements des Agro-procédés, Cemagref, 361 rue J.-F. Breton, B.P. 5095, 34033 Montpellier cedex 1). Thanks are also due to S. Huberson (Laboratoire d'Etudes Aérodynamiques, SP2MI Bd. 3 Téléport 2 - BP 179, 86960 Futuroscope cedex).

\section{References}

Chaplin J; Wu C (1989). Dynamic modelling of field sprayers. Transactions of the ASAE, 32(6), 1857-1863

De Baerdemaeker J S; Jaques M; Verdonck E (1983). Modelling the dynamic behaviour of sprayers booms. ASAE Paper No. 83-1507, St Joseph, MI, 15 p

Enfält P; Enggvist A; Alness K (1997). Assessment of the dynamic spray distribution on a flat surface using image analysis. Optimising Pesticide applications, Aspects of Applied Biology, 48, 17-24

ISO 5682/1 (1981). Equipment for crop protection - spraying equipment - part 1 : test methods of sprayer nozzles. International Standard Organisation, Geneva, Switzerland, $14 \mathrm{p}$

Langenakens J J; Ramon H; De Baerdemaeker J (1995). A model for measuring the effect of tire pressure and driving speed on horizontal sprayer boom movements and spray pattern. Transactions of the ASAE, 38(1), $65-72$

Lardoux Y ; Sinfort C ; Enfält P ; Sevila F (2007). Test method for boom suspension influence on spray distribution, part I: experimental study of pesticide application under a moving boom

Lebeau F (2003). Modélisation de la répartition dynamique au sol des produits phytosanitaires sous une rampe de pulvérisation. [Modelisation of the dynamical ground pattern of pesticides under a boom sprayer] Thèse de Doctorat, FUSAGx, Belgium, 197 p

Pochi D; Vanucci D (2002). Prediction of pesticide distribution on the ground based on sprayer movements. The CIGR Journal of Scientific Research and Developement, 4, Manuscript PM01001 
Author-produced version of the article published in Biosystems Engineering, 96(2), 161-168.

Original version available at www.elsevier.com - doi:10.1016/j.biosystemseng.2006.10.003

Rabatel G; Bourely A; Sevila F (1991). Object detection with machine vision in outdoor complex scenes: the case of robotic harvest of apples. Proceedings of EURISCON 95, Corfu (Grèce), June

Ramon H; De Baerdemaeker J (1997). Spray boom motions and spray distribution: Part 1, derivation of a mathematical relation. Journal of Agricultural Engineering Research, 66, 23-29

Sinfort C; Bonicelli B (1989). Implementation of a vibration testing bench for agricultural vehicles. 11 ${ }^{\text {th }}$ International Congress on Agricultural Engineering, Dublin 1989, 8 p

Sinfort C; Miralles A; Sevila F; Maniere G (1994). Study and development of a test method for spray boom suspensions. Journal of Agricultural Engineering Research, 59, 242-252

Sinfort C; Schmidt K; Rabatel G; Lardoux Y; Bonicelli B (1998). Test method for field sprayer inspection at the farm level. EurAgEng Paper No. 98A024. AgEng International Conference on Agricultural Engineering, Oslo, Norway, 24-27 August

SPECS (1998). European system for field sprayer inspection at the farm level. Final Report: 1 November 1994 30 April 1998. AIR3-CT94-1170. Katholieke Universiteit Leuven, Belgium

Speelman L; Jansen J W (1994). The effect of spray-boom movement on the liquid distribution of field crop sprayers. Journal of Agricultural Engineering Research, 19, 117-129

Vannuci D; Pari L; Fedrizzi M; Menesatti P (1992). Study of an automatic system to determine the spraying boom lateral fluctuations. EurAgEng Paper No. 9205113-AgEng International Conference on Agricultural Engineering, Uppsala, Sweden 
Boom movements

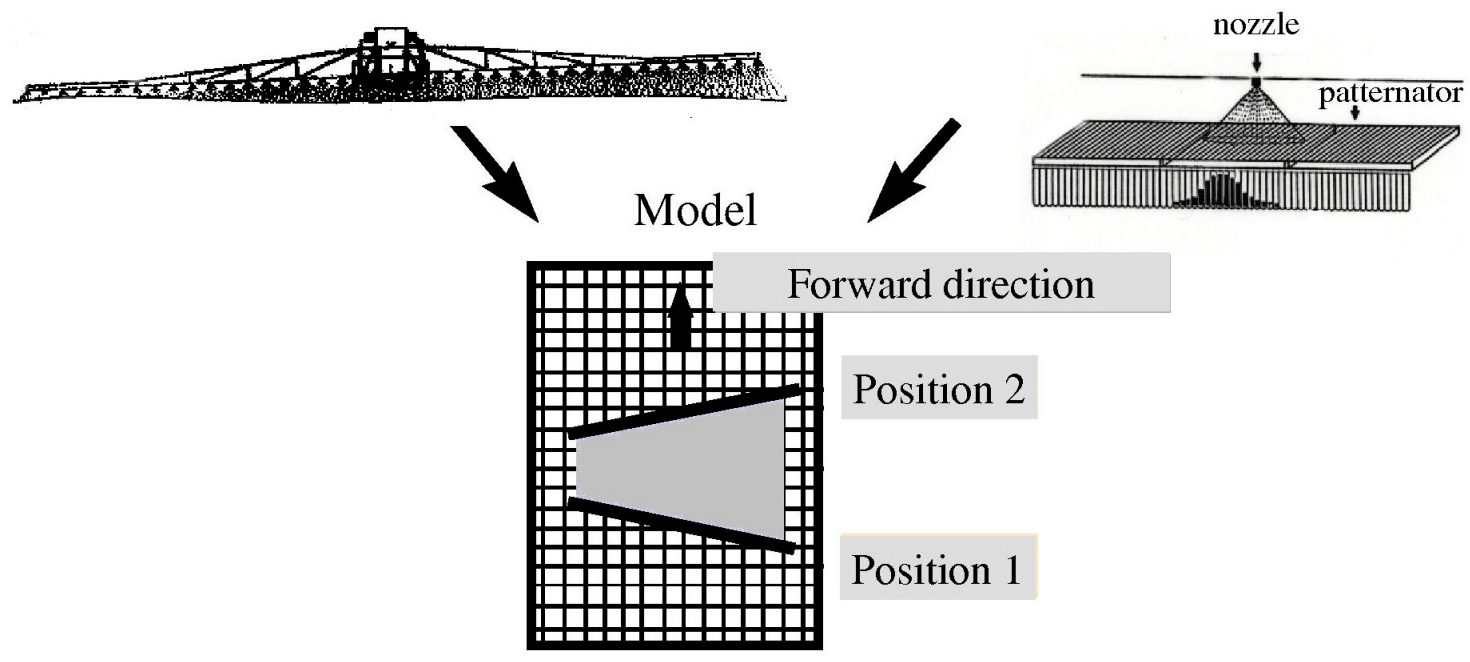

Fig. 1. Dynamic ground spray distribution model 
Author-produced version of the article published in Biosystems Engineering, 96(2), 161-168.

Original version available at www.elsevier.com - doi:10.1016/j.biosystemseng.2006.10.003

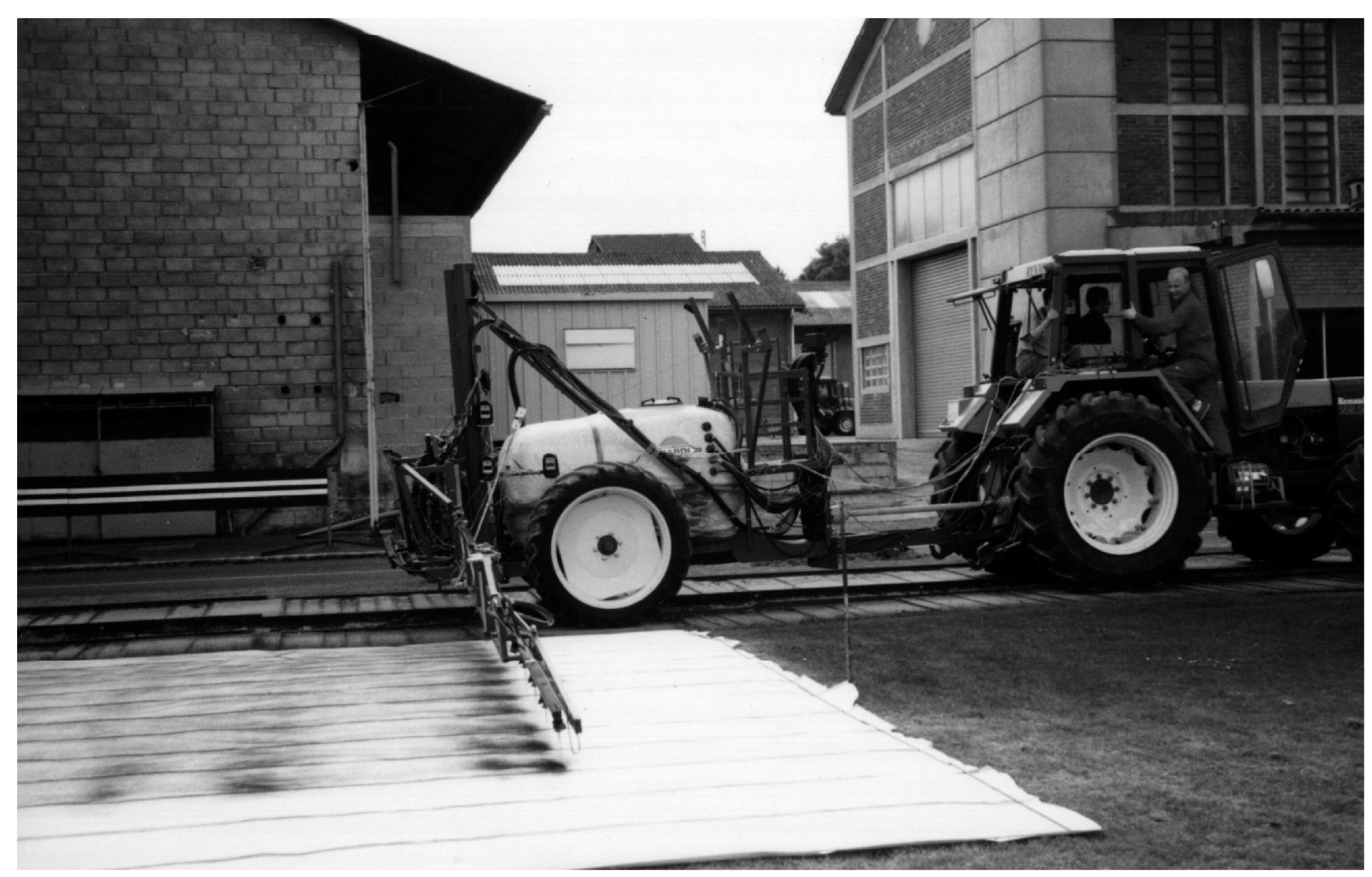

Fig. 2. Experimental test on concrete track 


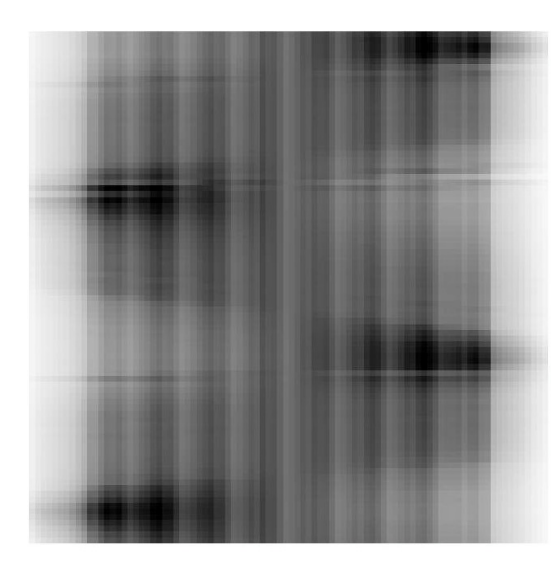

(a)
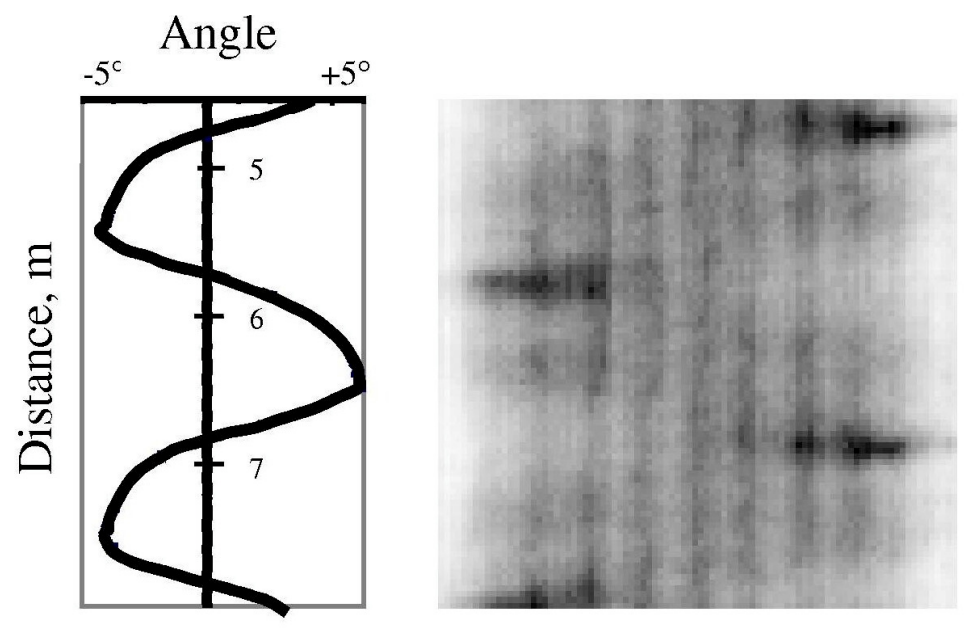

(b)

Fig. 3. Comparison between (a) simulated and (b) measured spray distributions for yaw movements: frequency of $0.77 \mathrm{~Hz}$, travel speed of $6 \mathrm{~km} / \mathrm{h}$ and boom height of $0.5 \mathrm{~m}$ 


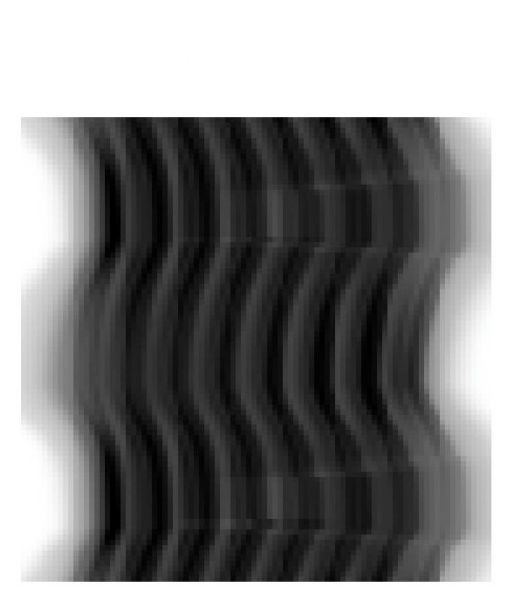

(a)

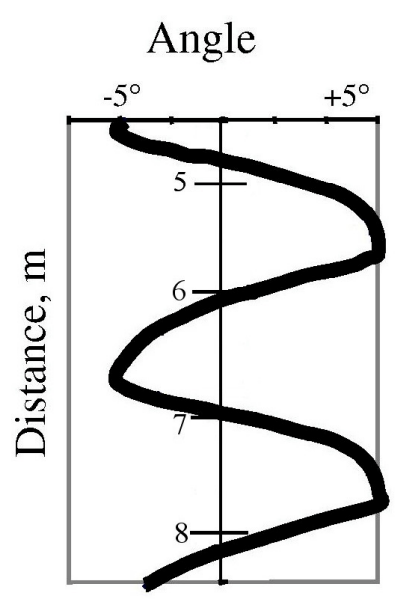

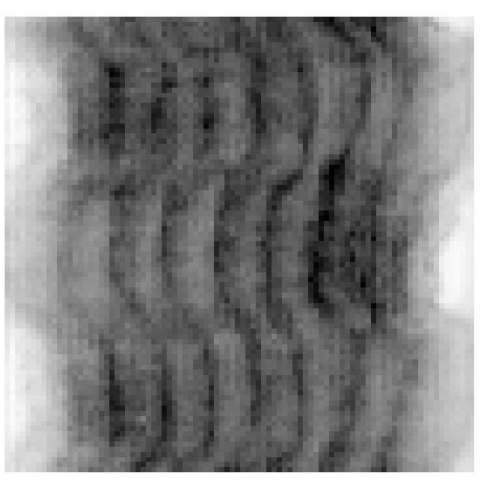

(b)

Fig. 4. Comparison between (a) simulated and (b) measured spray distributions for roll movements: frequency of $0.77 \mathrm{~Hz}$, travel speed of $6 \mathrm{~km} / \mathrm{h}$ and boom height of $0.5 \mathrm{~m}$ 
Author-produced version of the article published in Biosystems Engineering, 96(2), 161-168.

Original version available at www.elsevier.com - doi:10.1016/j.biosystemseng.2006.10.003

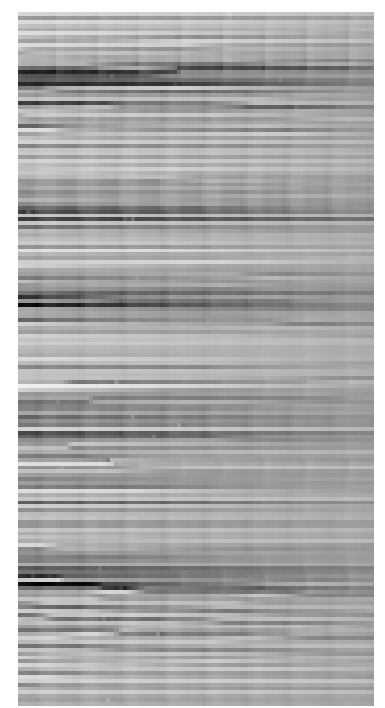

(a)

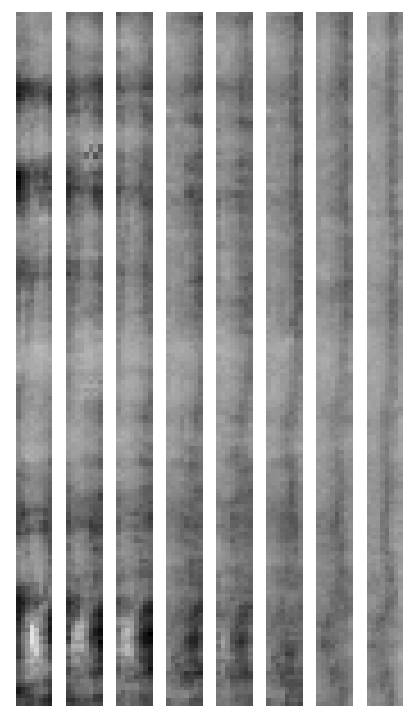

(b)

Fig. 5. Comparison between (a) simulated and (b) measured spray distributions on the bumpy track (sprayer type B) 


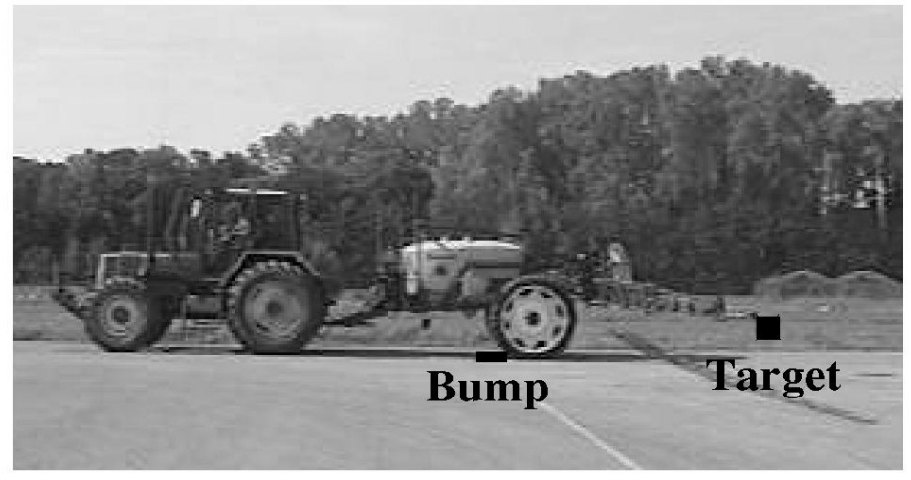

(a)

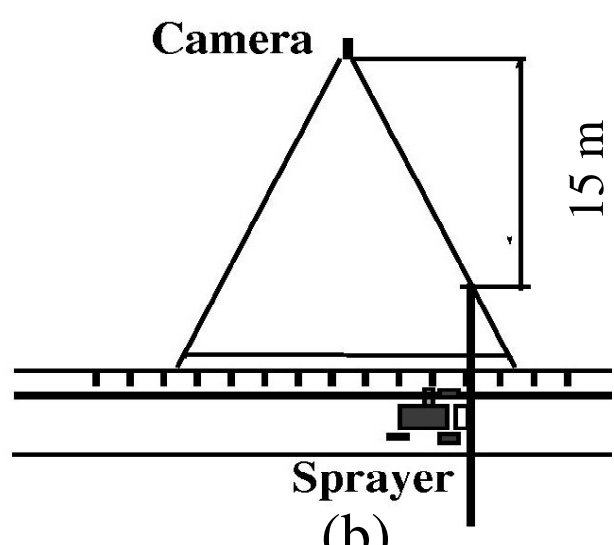

(b)

Fig. 6. Principle of the bump test: (a) test picture; (b) organisation chart 


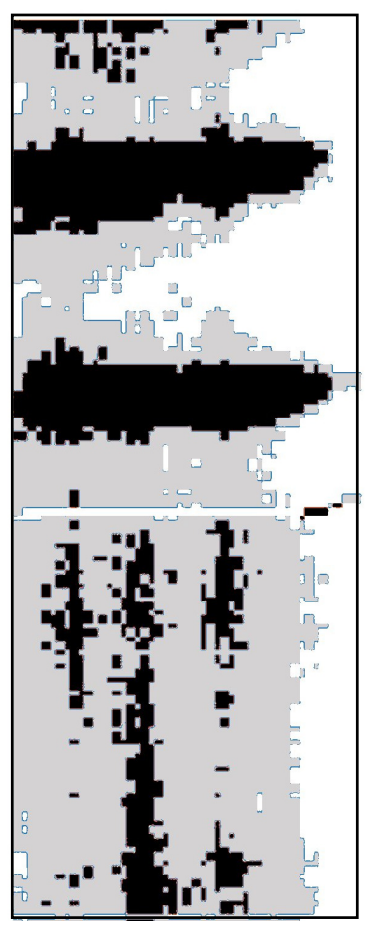

(a)

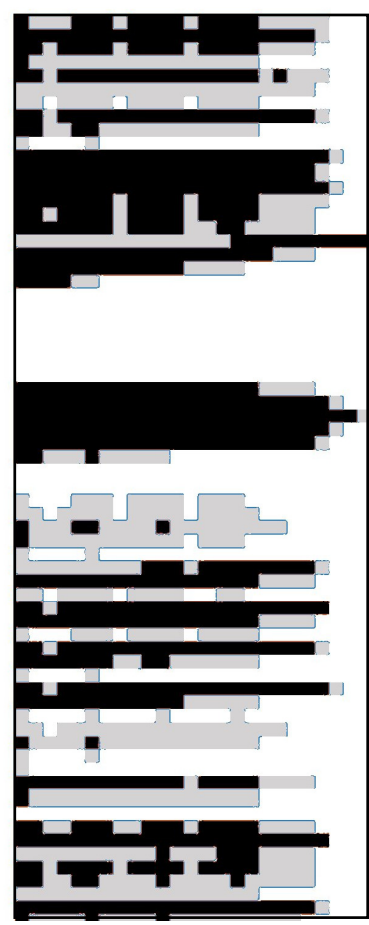

(b)

Fig. 7. (a) Measured and (b) simulated distributions obtained on the bump test with the new sprayer A, at $6 \mathrm{~km} / \mathrm{h}$ : black, over-sprayed areas; grey, correctly sprayed areas; white, undersprayed areas 